Voix et Images

voixetimages

\title{
Louise Gadbois « revisited »
}

\section{Jean-Pierre Duquette}

Volume 9, numéro 1, automne 1983

Guy Dufresne

URI : https://id.erudit.org/iderudit/200431ar

DOI : https://doi.org/10.7202/200431ar

Aller au sommaire du numéro

Éditeur(s)

Université du Québec à Montréal

ISSN

0318-9201 (imprimé)

1705-933X (numérique)

Découvrir la revue

Citer cet article

Duquette, J.-P. (1983). Louise Gadbois « revisited ». Voix et Images, 9(1),

167-169. https://doi.org/10.7202/200431ar

Ce document est protégé par la loi sur le droit d'auteur. L'utilisation des services d'Érudit (y compris la reproduction) est assujettie à sa politique d'utilisation que vous pouvez consulter en ligne.

https://apropos.erudit.org/fr/usagers/politique-dutilisation/
Cet article est diffusé et préservé par Érudit.

Érudit est un consortium interuniversitaire sans but lucratif composé de l’Université de Montréal, l'Université Laval et l'Université du Québec à Montréal. Il a pour mission la promotion et la valorisation de la recherche. https://www.erudit.org/fr/ 


\title{
ARTS
}

\section{Louise Gadbois «revisited»}

\author{
par Jean-Pierre Duquette, Université McGill
}

Pour toutes sortes de raisons, la carrière de Louise Gadbois s'est déroulée pour ainsi dire en dents de scie, et son œuvre est restée plus ou moins confidentielle. Elle est en grande forme, portant allègrement ses quatre-vingts ans passés, et elle vit toujours à Montréal. Autodidacte, elle a néanmoins étudié le dessin sous la direction de Holgate vers 1932-36, et elle a pris quelques cours de peinture avec Lyman à la fin des années trente. Jusqu'en 1960 environ elle n'a cessé de produire, pour s'interrompre presque complètement pendant une dizaine d'années. Femme, bourgeoise, épouse et mère : on comprend que ce quadruple «handicap» ait 'sérieusement entravé une trajectoire d'artiste dans la première moitié du siècle au Québec. Envers et contre tout, forte de l'amitié et des encouragements chaleureux du Père Couturier et de quelques autres, elle a poursuivi son œuvre avec ténacité. C'est le fruit d'une cinquantaine d'années de travail que la Galerie UQAM révélait à plusieurs en mars 1983. Préparée par Monique Brunet-Weinmann, cette rétrospective complétait en l'enrichissant considérablement l'exposition de portraits de L. Gadbois (1936-1955) au Musée d'art contemporain, hiver 1979.

Membre fondateur de la Société d'art contemporain en 1939, elle fut au centre même de l'activité picturale qui se déployait dans le dynamisme et l'effervescence des années précédant la formation (tacite) du groupe automatiste; ses premières leçons de dessin remontaient déjà à l'époque de ses études secondaires au Couvent Jésus-Marie d'Outremont. Puis elle continue de travailler seule, en amateur et de manière plus ou moins sporadique, jusqu'à sa venue chez Holgate en 1932. Entre temps elle s'était mariée et elle avait donné naissance à six enfants. À la veille de la guerre elle suivait quelques cours de peinture chez Lyman. Au moment où la S.A.C. se saborde, en 1948, Louise Gadbois vient de passer le cap de la cinquantaine. Son ouvre n'est pas dans le circuit des galeries commerciales : d'une part elle ne veut dépendre de personne, et puis dans le milieu qui est le sien, on ne commercialise pas sa production quand on est une femme, à moins de nécessité financière. Outre cela, un certain isolement, la perte du contact 
avec le monde actif de l'art, et bientôt la montée du mouvement abstrait en peinture ralentissent son labeur. Des deuils intimes, le départ des enfants achèvent de la désemparer. Et son oeuvre, peu vue du grand public, tombera peu à peu dans l'oubli malgré des expositions assez nombreuses (mais toujours «hors-circuit» : Collège Marie de France, Séminaire de Joliette, Collège de Saint-Laurent, Théâtre de la Poudrière, Centre culturel de Verdun, Collège André-Grasset, etc.). Ce n'est finalement que début 1979, au Musée d'art contemporain, que les portraits peints au cours d'une vingtaine d'années refont surface. Elle s'était remise à travailler de façon soutenue en 1967 et elle n'a pas cessé jusqu'aujourd'hui. En 1979, l'exposition du M.A.C. et un premier séjour en Provence redonnaient à Louise Gadbois son enthousiasme de jeunesse face à son projet de peintre et de dessinateur.

La rétrospective de la Galerie UQAM présentait un vaste panorama de cette production riche et séduisante : 30 dessins et environ 90 tableaux de toutes les époques. Gadbois est d'abord un dessinateur : ses années chez Holgate confirment un talent et une maîtrise indéniables (après quatre ans de travail sous sa direction, celui-ci la renvoie chez elle en lui affirmant qu'il n'a plus rien à lui apprendre...). Dans des fragments d'entretien reproduits au catalogue, l'artiste rappelle le sens de «l'enseignement» de Holgate : «Il fallait étudier l'anatomie, beaucoup. Il était exigeant sur ce point. Mais il ne prétendait pas enseigner : il dirigeait. Il nous laissait libres de dessiner, et ensuite faisait la critique sans jamais mettre un coup de crayon sur le dessin lui-même». Elle se libérera très vite du souci un peu scolaire des volumes et des modelés fidèlement anatomiques pour pratiquer un dessin plus linéaire, simplifié, dépouillé, qui exprime sobrement l'essentiel d'un être, d'une personnalité (admirable «Dessin de ma mère», en 1933, à la charnière entre les deux façons; et davantage dans le fusain des années quarante représentant le Père Couturier; plus encore dans le portrait de Viola Léger, de 1969).

La peinture, autant les paysages que les portraits et les natures mortes, s'avère peut-être plus vraiment inventive, plus personnelle, malgré l'apparente influence, ici et là, de Derain, du cubisme, ou le caractère un peu cézannien de certains aplats ou de certaines compositions. Les portraits les plus exceptionnels des années quarante sont sans contredit ceux qui appartiennent aux collections du Musée du Québec, ce dont on ne peut que se réjouir : le «Victor Barbeau» dont le gilet rouge chante dans le gris du costume et des fonds; la «Femme en jaune», avec son corsage lumineux sur les gris et les noirs; la célèbre "Réfugiée» avec son châle brun-orangé sur la robe sombre et le fond grisâtre; le "Père Couturier" ascétique, presque désincarné, au regard pénétrant derrière les grosses lunettes rondes; et «Madame Borduas» en corsage jaune, acide, sur l'arrière-plan gris. Autant de tableaux inoubliables qui marquent d'une manière définitive l'évolution du portrait dans l'art québécois. On pense encore à «Plasse LeCaisne tisserand», daté de 1948; à la «Femme en brun» (1946); à la «Femme au 
coussin rose», de 1941; à "Géraldine aux citrons» (1944); ou bien à la «Jeune fille pensive», vers 1948.

Les paysages sont en général moins «libres», plus astreints aux strictes données du réel, au-delà d'un travail de simplification évident, de réduction à l'essentiel de la perspective; un certain humour, dirait-on, ou une naïveté assumée préside à la mise en place des composantes de la vue, du cadrage; presque toujours on note un climat intimiste, comme un apprivoisement de la nature, même dans les champs plus ouverts, les espaces plus étendus. Il est vrai que le format en général modeste des toiles contribue à créer cette impression d'une nature proche du spectateur, familière, aimable. Les natures mortes ont également ce caractère d'intimité, bien entendu, de proximité; le plus souvent, le regard du peintre envisage un coin de table limité, sans échappée profonde. Les objets de tous les jours s'y retrouvent en compositions sereines : pichet,plat, théière; des fruits sur un compotier, quelques fleurs, des dominos en vrac, une cigarette qui fume dans le cendrier, le dossier d'une chaise rustique. La couleur s'éclaircit de façon très marquée à mesure qu'on en vient à des ceuvres plus récentes : un jaune très lumineux tend à flotter partout, en même temps qu'augmente le dépouillement de la toile comme dans «Coquelicots d'avril» (1981) où le rouge des pavots éclate bruyamment dans la brillante luminosité de l'arrière-plan.

Oeuvre attachante que celle de Louise Gadbois, et qui répond en tous points, depuis les débuts jusqu'à maintenant, aux conseils que le Père Couturier, rentré en France après la guerre, lui adressait dans ses lettres : "Faites donc simplement ce qui vous chante : c'est aussi probablement ce qui chante en vous) (16 février 1947); ceci encore, le 31 mai 1948 : «Travaillez paisiblement dans votre voie, ne vous souciant pas trop des contemporains, pensant seulement à faire des choses conformes à votre goût et à ses intuitions». Elle reprend, grâce à cette rétrospective, sa vraie place dans l'histoire de la peinture moderne au Québec. 